\title{
Structure of a Discrete Hexadecameric Water Cluster in a Metal- Organic Framework Structure
}

Sujit K. Ghosh and Parimal K. Bharadwaj

Department of Chemistry, Indian Institute of Technology Kanpur 208016, India

$\underline{\text { Supplementary Material }}$ 


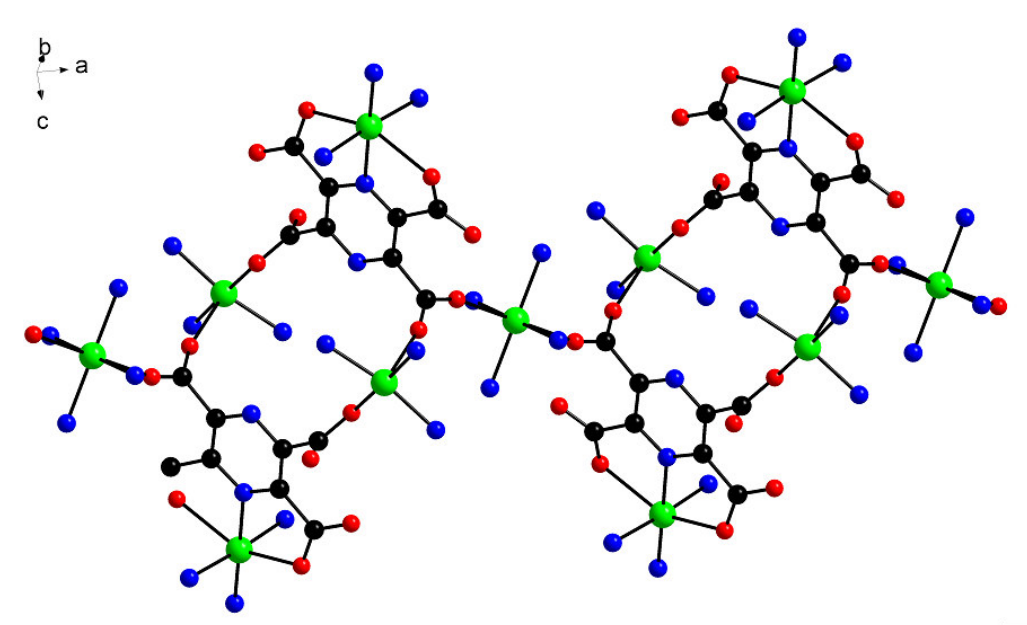

器

Figure S1. An illustration of the binding mode of pyrazine-2,3,5,6-tetracarboxylate with $\mathrm{Cu}$ (II). The lone blue spheres are pyridine $\mathrm{N}$ atoms. The entire pyridine molecule is not shown for clarity.

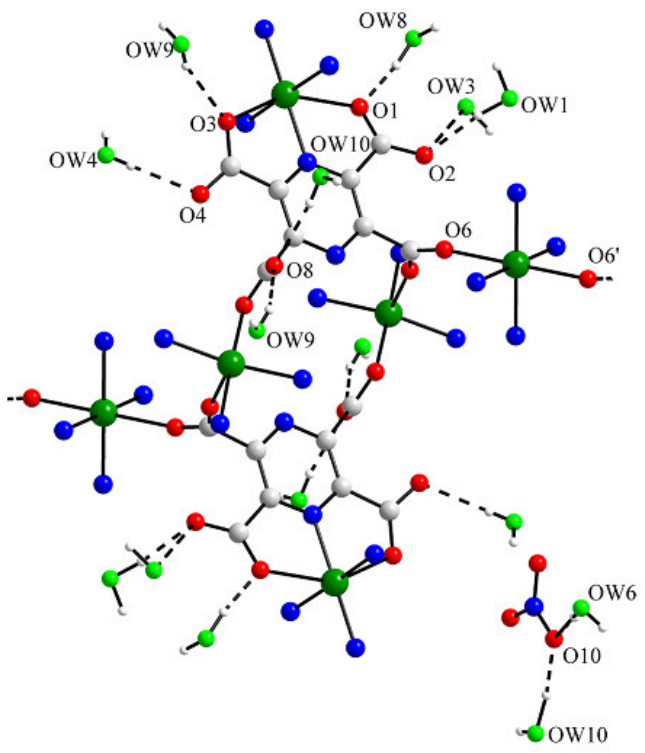

Figure S2. An illustration showing how water molecules are bound to the MOF. The lone blue spheres are pyridine $\mathrm{N}$ atoms. The entire pyridine molecule is not shown for clarity. 


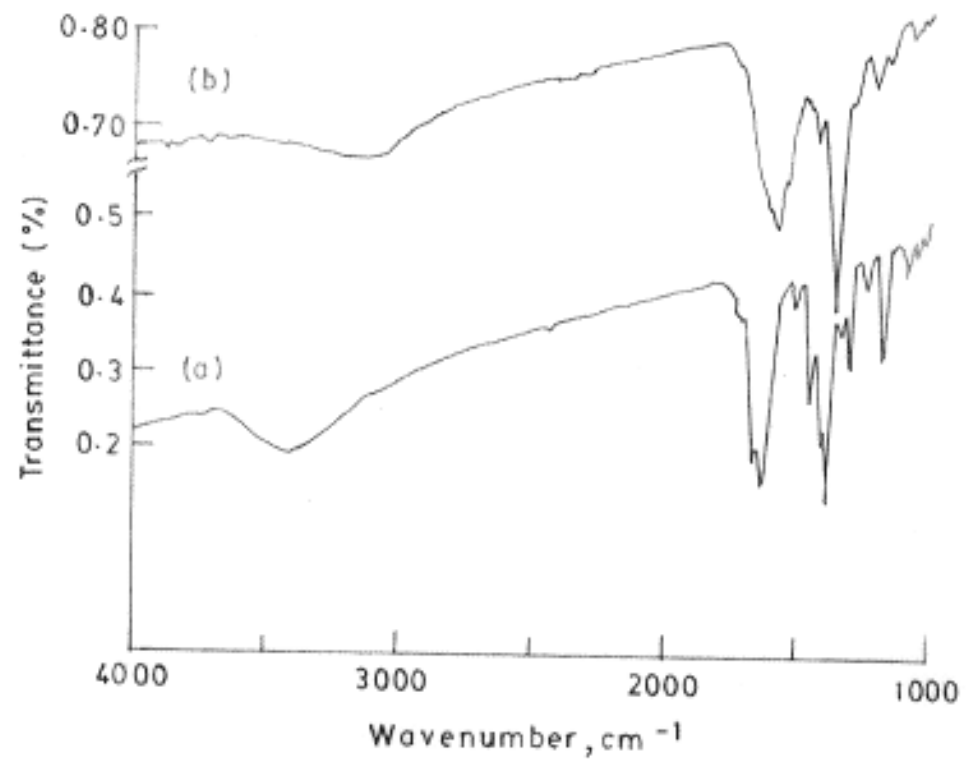

Figure S3. The infrared spectra of $\mathbf{1}$ (a) before water removal and (b) after water removal.

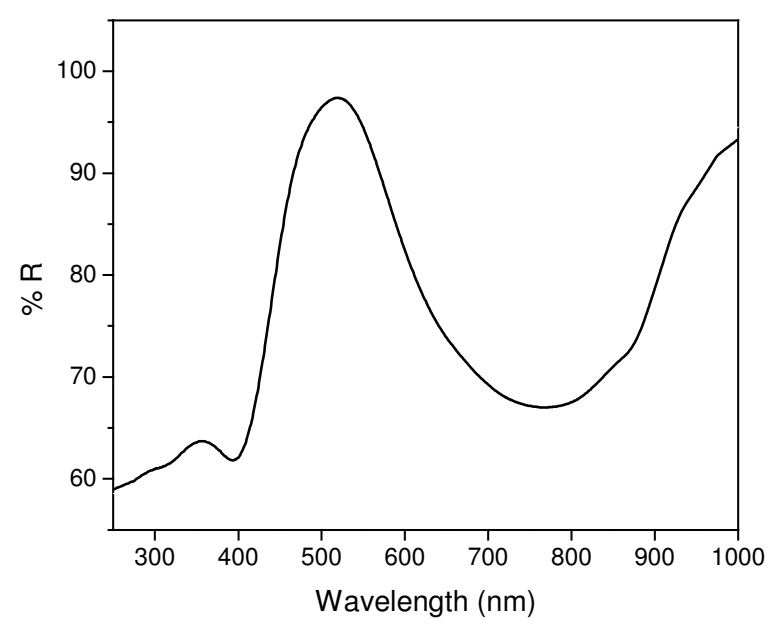

Fig. S4. The reflectance spectrum of $\mathbf{1}$ at $300 \mathrm{~K}$. 


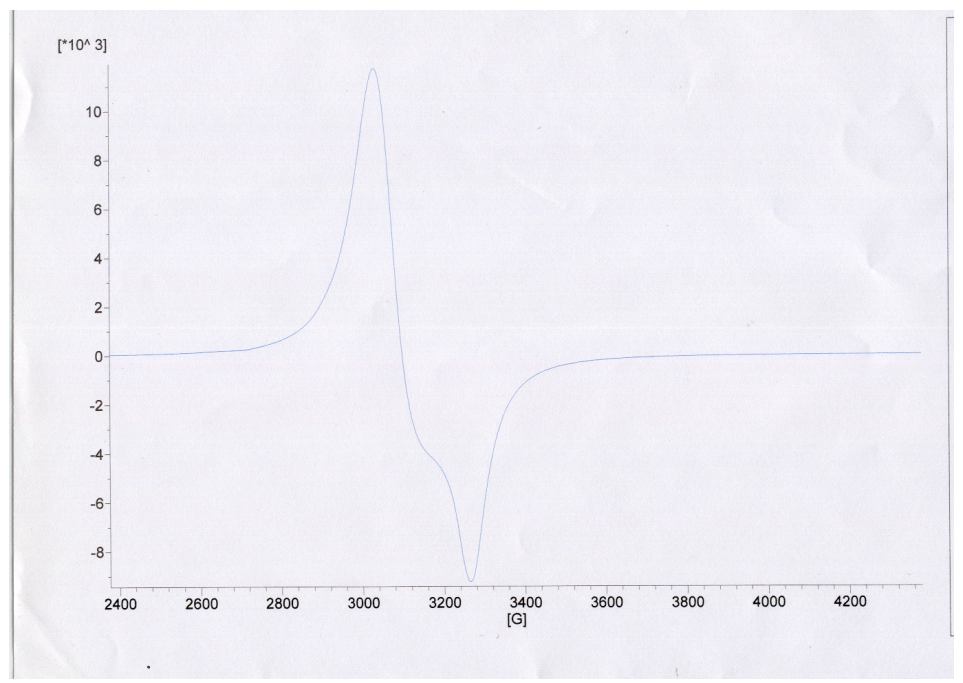

Fig. S5 . The EPR spectrum of $\mathbf{1}$ in the solid state at $120 \mathrm{~K}$

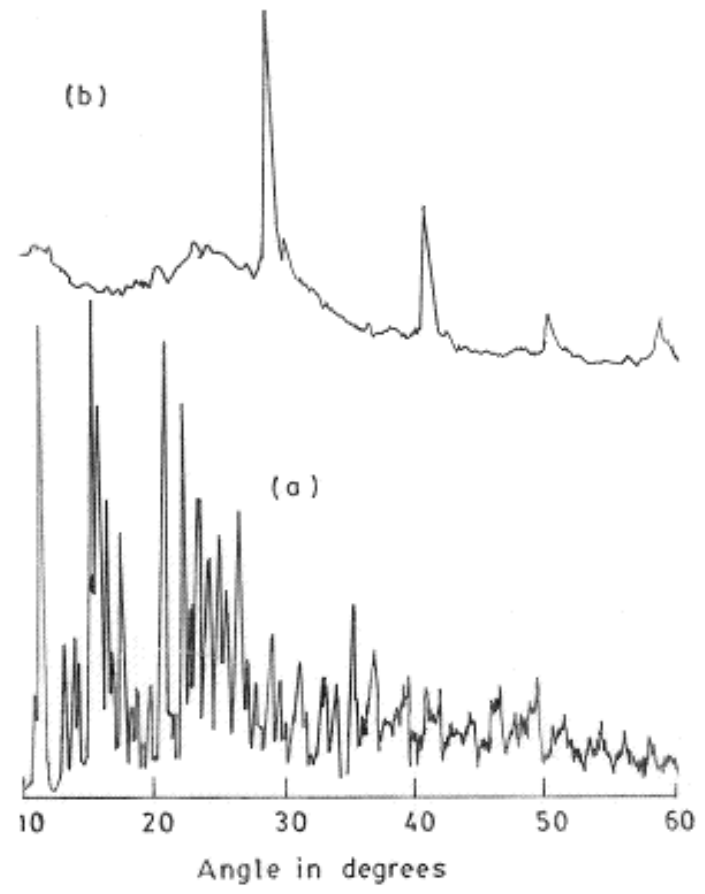

Figure S6. (a) Simulated X-ray powder diffraction pattern of 1. (b) Powder X-ray diffraction of $\mathbf{1}$ after water exclusion. 


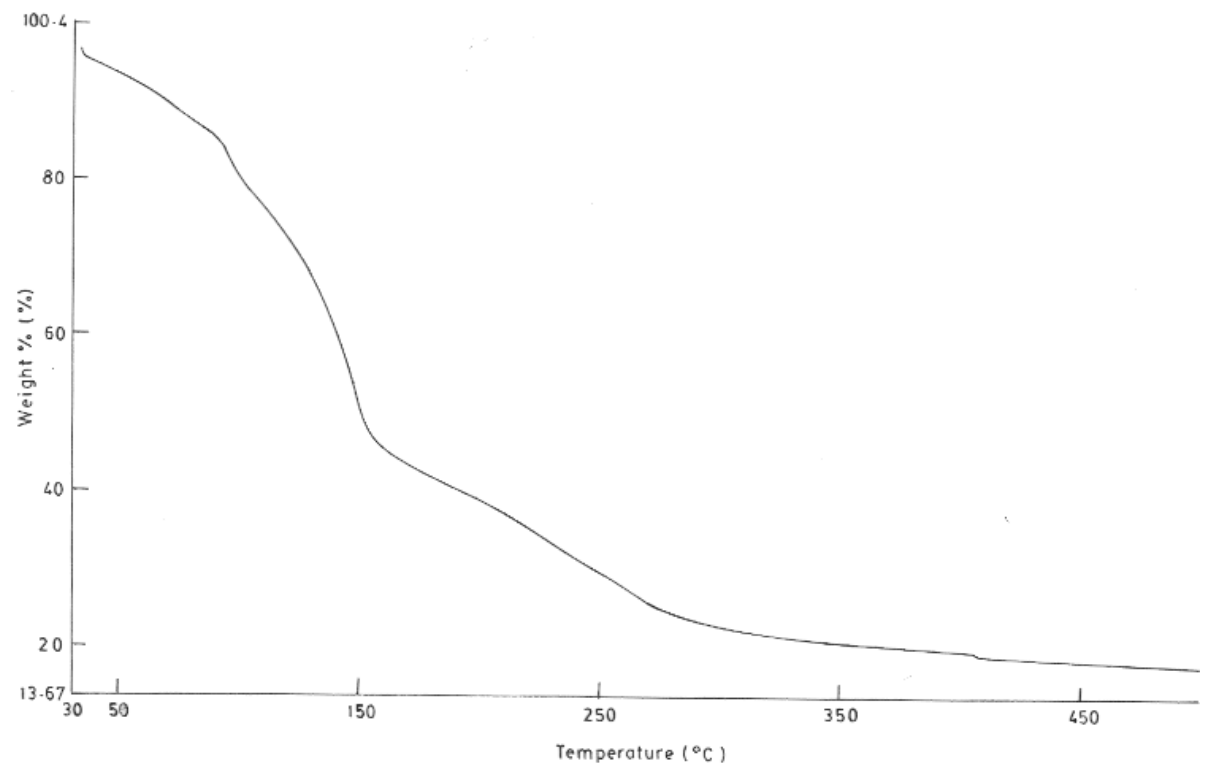

Figure S7. TGA curve for compound 1 